\title{
Working with dauer larvae
}

\author{
Xantha Karp ${ }^{\S}$
}

Department of Biology, Central Michigan University, Mount Pleasant, MI 48859 USA

\section{Table of Contents}

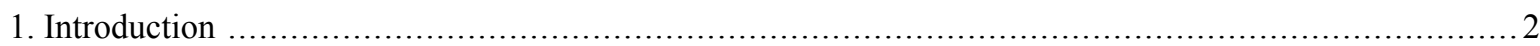

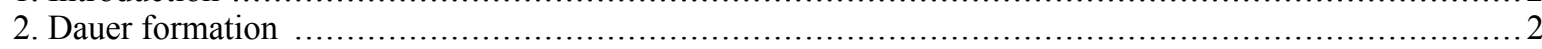

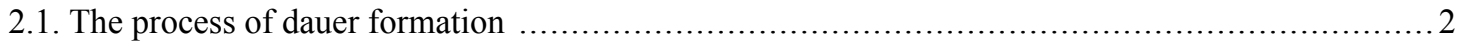

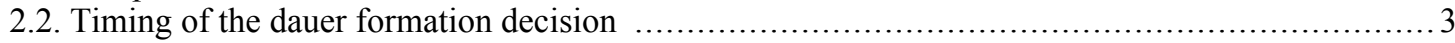

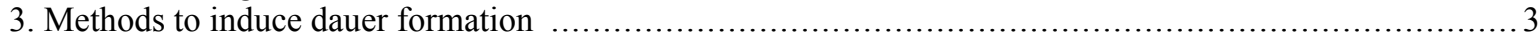

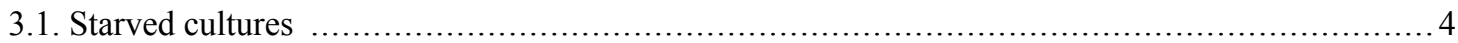

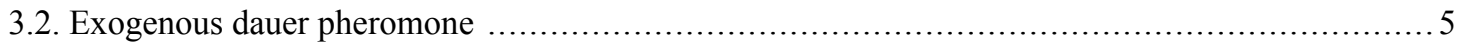

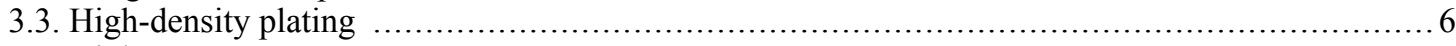

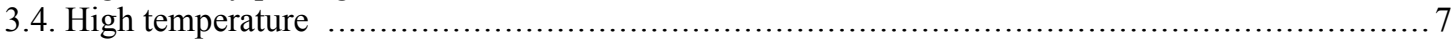

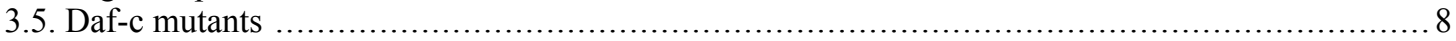

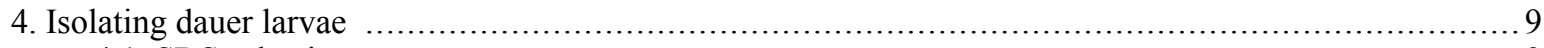

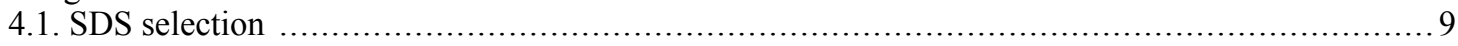

4.2. Fluorescent beads …………

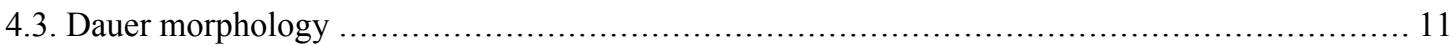

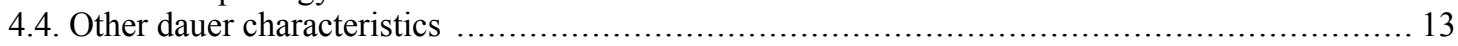

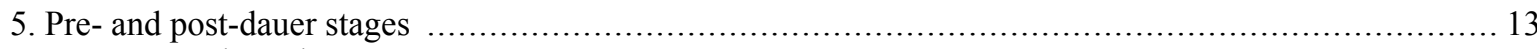

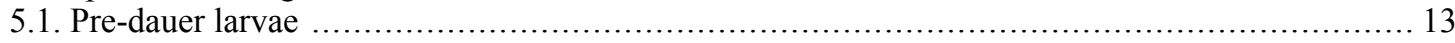

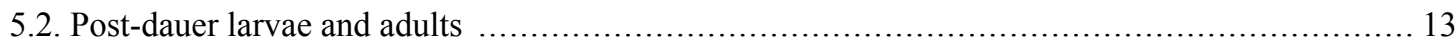

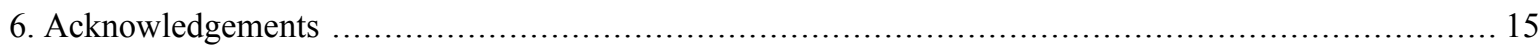

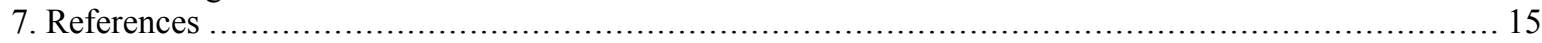

\begin{abstract}
Dauer diapause is a stress-resistant, developmentally quiescent, and long-lived larval stage adopted by Caenorhabditis elegans when conditions are unfavorable for growth and reproduction. This chapter contains methods to induce dauer larva formation, to isolate dauer larvae, and to study pre- and post-dauer stages.
\end{abstract}

\footnotetext{
${ }^{*}$ Edited by Oliver Hobert. Last revised May 4, 2016. Published in its final form August 9, 2018. This chapter should be cited as: Karp X. Working with dauer larvae. (August 9, 2018), WormBook, ed. The C. elegans Research Community, WormBook, doi/10.1895/

wormbook.1.180.1, http://www.wormbook.org.

Copyright: ( 2016 Xantha Karp. This is an open-access article distributed under the terms of the Creative Commons Attribution License, which permits unrestricted use, distribution, and reproduction in any medium, provided the original author and source are credited.

${ }^{\S}$ To whom correspondence should be addressed. Email: karp1x@cmich.edu
} 


\section{Introduction}

The dauer larva is a stress-resistant, developmentally arrested stage formed in response to adverse environmental conditions (Figure 1). In the wild, $C$. elegans is most often found in the dauer stage (Barrière and Félix, 2005). Dauer larvae are morphologically distinct from other stages, display an altered metabolism, and express different genes (reviewed in the WormBook chapter Dauer and in Fielenbach and Antebi, 2008). Dauer formation occurs immediately after the second larval molt (Cassada and Russell, 1975; Golden and Riddle, 1984b). If favorable environmental conditions are again encountered, dauer larvae recover and complete reproductive development. Time spent in the dauer stage does not affect the pattern or sequence of cell divisions during post-dauer development, nor does it shorten the adult lifespan (Klass and Hirsh, 1976; Liu and Ambros, 1991; Euling and Ambros, 1996; Braendle and Félix, 2008). The process and regulation of dauer formation have been extensively studied to learn about signal transduction, neuronal function and remodeling, development, stress resistance, and aging, among other topics. This chapter details methods that are used to study dauer larvae, as well as pre- and post-dauer larvae.

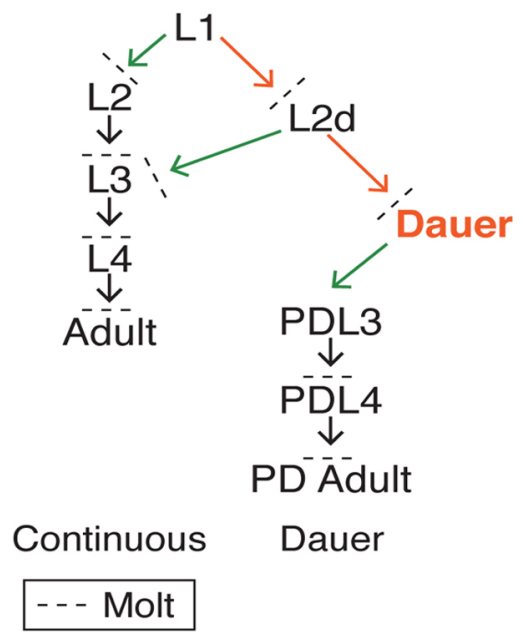

Figure 1. Dauer and continuous life histories. C. elegans can develop through distinct life histories, depending on environmental conditions. Favorable environments including plentiful food, sparse population, and moderate temperatures promote continuous development (left). Adverse environments including inadequate food, high population density, and elevated temperatures promote dauer development (right). Environmental conditions are assessed at the L1 and L2 stages. Green arrows indicate developmental progression in favorable conditions; red arrows indicate developmental progression (or arrest) in adverse conditions. Dauer development is delayed relative to continuous development, such that dauer larvae form at approximately the same chronological time as continuously developing larvae reach the L4 stage. All stages shown are separated by molts, except there is no molt between dauer and PDL3. See text for more details. PD = post-dauer.

\section{Dauer formation}

\subsection{The process of dauer formation}

The dauer formation decision is complex, and the outcome greatly impacts the survival of the individual and its progeny. Developing larvae sense cues from their environment. Specific neurons interpret these cues, and translate them into modulation of several interconnected signal transduction pathways. Ultimately, this modulation gives rise to a specific outcome to enter dauer or to develop continuously. A great deal is known about these steps, reviewed in other WormBook chapters and elsewhere (Dauer; Fielenbach and Antebi, 2008). Here a brief outline of this decision is provided, focused on the aspects that are relevant to the methods described below.

\subsubsection{Environmental cues}

The best understood environmental cues are those that have been most extensively used to experimentally manipulate dauer formation: dauer pheromone and temperature. Early descriptions of dauer larvae noted the existence of a chemical present in the medium in which worms have grown that stimulates larvae to enter dauer (Cassada and Russell, 1975). Soon thereafter, crude dauer pheromone was extracted from such media and demonstrated to induce dauer formation when added to fresh plates (Golden and Riddle, 1982). It was noted that the concentration of pheromone per se was less important than the ratio of pheromone to the bacterial food source (Golden and Riddle, 1982; Golden and Riddle, 1984c). Now, the "pheromone" is known to comprise a mix of 
ascarosides (Jeong et al., 2005; Butcher et al., 2008). The precise composition of this mix varies with developmental stage and environmental conditions (Butcher et al., 2008; Kaplan et al., 2011). Interestingly, individual isolates of wild $C$. elegans vary in the ascaroside mixtures they produce, and in their response to those mixtures (Diaz et al., 2014). The molecule(s) that make up the "food cue" are less well characterized, but include bacterial fatty acids (Kaul et al., 2014). The CMK-1 kinase is required for sensation of the food cue (Neal et al., 2015).

Temperature also greatly impacts dauer formation. Genetically identical larvae grown in otherwise identical conditions can display vastly different dauer formation responses at different temperatures. In general, higher temperatures induce more dauer formation. Wild-type larvae grown in sparse population density (i.e., low pheromone) do not enter dauer at $15^{\circ} \mathrm{C}, 20^{\circ} \mathrm{C}$, or $25^{\circ} \mathrm{C}$, but some do enter dauer at $27^{\circ} \mathrm{C}$ (see below) (Ailion and Thomas, 2000). Wild-type larvae grown on pheromone will enter dauer at higher penetrance at $25^{\circ} \mathrm{C}$ than at lower temperatures (Golden and Riddle, 1984a). Similarly dauer-constitutive (Daf-c) mutants are frequently temperature-sensitive, entering dauer at $25^{\circ} \mathrm{C}$ but with lower penetrance or not at all at lower temperatures (see Section 3.5) (Riddle et al., 1981; Swanson and Riddle, 1981). This temperature sensitivity is most often due to the inherent temperature dependence of the dauer formation decision, rather than due to the production of an unstable protein (Golden and Riddle, 1984a).

\subsubsection{Signaling pathways}

Dauer-promoting environmental cues impact several signal transduction pathways that regulate dauer formation including cGMP, TGF $\beta$, insulin-like, and nuclear hormone receptor pathways. The convergence of these pathways to regulate the dauer formation is reviewed in Dauer; and Fielenbach and Antebi (2008), whereas specific pathways are reviewed in the following WormBook chapters: TGF- $\beta$ signaling in $C$. elegans, Insulin/insulin-like growth factor signaling in C. elegans, and Nuclear receptor signal transduction in C. elegans.

\subsection{Timing of the dauer formation decision}

The dauer formation decision occurs during the first two larval stages in wild-type larvae (see Figure 1). During the L1 stage, the decision is made whether to enter the pre-dauer L2d stage or to enter the more rapid L2 stage. Entry to L2 essentially commits the larva to continuous development, whereas L2d larvae continue to respond to environmental cues to decide whether to molt into dauer larvae or L3 larvae. The commitment to dauer entry does not occur until mid-late L2d stage (Golden and Riddle, 1984b; Schaedel et al., 2012). Thus, for the highest penetrance of dauer formation, it is advisable to grow wild-type larvae in dauer-inducing conditions until they enter the L2d-dauer molt (Golden and Riddle, 1984b).

Daf-c mutants, by contrast, display a temperature-sensitive period around the L1 molt (Swanson and Riddle, 1981). Thus, Daf-c mutants grown at $25^{\circ} \mathrm{C}$ through the $\mathrm{L} 1$ molt will be committed to dauer formation; conversely, these strains grown at $15^{\circ} \mathrm{C}$ through the $\mathrm{L} 1$ molt will be committed to continuous development.

\section{Methods to induce dauer formation}

Table 1 briefly summarizes the information in Section 3, so that different methods can be compared. It is important to note that subtle changes in environmental conditions can impact dauer formation, particularly when the strains are near the threshold for the dauer formation decision (Table 2). It is always advisable to grow controls strictly in parallel with experimental animals for studies involving dauer formation.

Table 1: Comparison of dauer induction methods

\begin{tabular}{|c|c|c|c|c|c|c|c|c|}
\hline $\begin{array}{l}\text { Method of } \\
\text { inducing } \\
\text { dauer }\end{array}$ & $\begin{array}{l}\text { Stages } \\
\text { easily } \\
\text { studied }\end{array}$ & Plates & Temp & $\begin{array}{l}\text { Control } \\
\text { time } \\
\text { in dauer }\end{array}$ & $\begin{array}{l}\text { Penetrance } \\
\text { of dauer } \\
\text { formation }\end{array}$ & $\begin{array}{l}\text { Genetic } \\
\text { background }\end{array}$ & $\begin{array}{l}\text { Can induce } \\
\text { dauer } \\
\text { formation in } \\
\text { Daf-d strains }\end{array}$ & Other \\
\hline $\begin{array}{l}\text { Starved } \\
\text { plate }\end{array}$ & $\begin{array}{l}\text { Dauer } \\
\text { Post-dauer }\end{array}$ & NGM & Any & No & $\begin{array}{l}\text { Variable; } \\
\text { other stages } \\
\text { on plates }\end{array}$ & Any & No & $\begin{array}{l}\text { Simplest } \\
\text { method }\end{array}$ \\
\hline $\begin{array}{l}\text { Dauer } \\
\text { pheromone/ } \\
\text { ascarosides }\end{array}$ & $\begin{array}{l}\text { Pre-dauer } \\
\text { Dauer } \\
\text { Post-dauer }\end{array}$ & $\begin{array}{l}\text { NGM + } \\
\text { pheromone/ } \\
\text { ascarosides }\end{array}$ & $\begin{array}{l}\text { Any; } \\
\text { best at } \\
25^{\circ} \mathrm{C}\end{array}$ & Yes & $\begin{array}{l}\text { Variable, } \\
\text { depending } \\
\text { on prep }\end{array}$ & Any & $\begin{array}{l}\text { Possible, } \\
\text { depending } \\
\text { on prep }\end{array}$ & \\
\hline
\end{tabular}




\begin{tabular}{|c|c|c|c|c|c|c|c|c|}
\hline $\begin{array}{l}\text { Method of } \\
\text { inducing } \\
\text { dauer }\end{array}$ & \begin{tabular}{|l|} 
Stages \\
easily \\
studied
\end{tabular} & Plates & Temp & \begin{tabular}{|l} 
Control \\
time \\
in dauer
\end{tabular} & $\begin{array}{l}\text { Penetrance } \\
\text { of dauer } \\
\text { formation }\end{array}$ & \begin{tabular}{|l|} 
Genetic \\
background
\end{tabular} & $\begin{array}{l}\text { Can induce } \\
\text { dauer } \\
\text { formation in } \\
\text { Daf-d strains }\end{array}$ & Other \\
\hline $\begin{array}{l}\text { High-density } \\
\text { plating }\end{array}$ & \begin{tabular}{|l|} 
Dauer \\
Post-dauer
\end{tabular} & $\begin{array}{l}\text { Egg white } \\
\text { plates }\end{array}$ & $\begin{array}{l}\text { Any; } \\
\text { best at } \\
25^{\circ} \mathrm{C}\end{array}$ & Yes & $\begin{array}{l}\text { Variable; } \\
\text { recover } \\
\text { dauers with } \\
1 \% \text { SDS }\end{array}$ & Any & $\begin{array}{l}\text { Possible, } \\
\text { when } \\
\text { combined } \\
\text { with high } \\
\text { temperature } \\
\left(27^{\circ} \mathrm{C}\right)\end{array}$ & \begin{tabular}{|l|} 
Difficult to \\
obtain dauers \\
in strains with \\
low brood \\
size
\end{tabular} \\
\hline $\begin{array}{l}\text { High } \\
\text { temperature } \\
\left(27^{\circ} \mathrm{C}\right)\end{array}$ & \begin{tabular}{|l|} 
Pre-dauer \\
Dauer
\end{tabular} & NGM & $27^{\circ} \mathrm{C}$ & $\begin{array}{l}\text { Yes- } \\
\text { but may } \\
\text { recover } \\
\text { spon- } \\
\text { taneously }\end{array}$ & $\begin{array}{l}\text { Low except } \\
\text { in mutant } \\
\text { background }\end{array}$ & $\begin{array}{l}\text { Higher } \\
\text { penetrance } \\
\text { in Hid* } \\
\text { background }\end{array}$ & $\begin{array}{l}\text { Some Daf-d } \\
\text { strains } \\
\text { become Daf-c } \\
\text { at } 27^{\circ} \mathrm{C}\end{array}$ & $\begin{array}{l}\text { Less healthy, } \\
\text { Some L1 \& } \\
\text { L2 arrest }\end{array}$ \\
\hline $\begin{array}{l}d a f-7 \\
(e 1372)\end{array}$ & \begin{tabular}{|l|} 
Pre-dauer \\
Dauer
\end{tabular} & NGM & $25^{\circ} \mathrm{C}$ & Yes & High & $\begin{array}{l}\text { Requires } \\
\text { daf-7 }\end{array}$ & $\begin{array}{l}\text { Yes: } \\
\text { mutations in } \\
\text { parallel or } \\
\text { upstream } \\
\text { pathways }\end{array}$ & $\begin{array}{l}\text { Moderate Egl, } \\
\text { Asynchronous } \\
\text { recovery }\end{array}$ \\
\hline $\begin{array}{l}d a f-2 \\
(e 1370)\end{array}$ & $\begin{array}{l}\text { Pre-dauer } \\
\text { Dauer }\end{array}$ & NGM & $25^{\circ} \mathrm{C}$ & Yes & High & $\begin{array}{l}\text { Requires } \\
\text { daf-2 }\end{array}$ & $\begin{array}{l}\text { Yes: } \\
\text { mutations in } \\
\text { parallel or } \\
\text { upstream } \\
\text { pathways }\end{array}$ & $\begin{array}{l}\text { Slow growth, } \\
\text { Pleiotropy, } \\
\text { Asynchronous } \\
\text { recovery }\end{array}$ \\
\hline
\end{tabular}

Table 2. Environmental factors that influence dauer formation in a laboratory setting

Temperature: Higher temperatures induce dauer formation (Golden and Riddle, 1984a).

Genetic background: In addition to characterized Daf mutations, many genes present in the background can modulate dauer formation when conditions are close to threshold (Harvey et al., 2009).

Presence of contaminating microorganisms: In general, mold and bacterial contamination inhibit dauer formation (Golden and Riddle, 1984c; X. Karp, unpublished observations).

Type of agar: Noble agar promotes dauer formation (Neal et al., 2013).

Humidity: C. elegans can sense humidity, and can migrate to a preferred humidity level based on association with past experience, including starvation (Russell et al., 2014). These findings suggest the possibility that dauer formation could be influenced by humidity. Rigorous tests of the precise effect of humidity on dauer formation are lacking, but in our hands humidity appears to promote dauer formation in response to exogenous pheromone (L. Nika and X. Karp, unpublished). However, it is not clear that humidity, if it does affect dauer formation, always does so in the same direction (S. Neal, personal communication). Carefully controlled experiments will be necessary to determine the magnitude and direction, if any, of these effects.

Other factors: The above list is undoubtedly not exhaustive. Care should be taken to grow control strains strictly in parallel with experimental strains, including using the same batch of plates, in order to minimize any environmental differences.

\subsection{Starved cultures}

When cultures of $C$. elegans become crowded and exhaust their food supply, dauer formation results (Cassada and Russell, 1975). Wild-type larvae typically do not enter dauer at temperatures at or below $25{ }^{\circ} \mathrm{C}$ when there is any food on the plate, even a small amount, unless high concentrations of pheromone are added by one of the 
methods discussed in Section 3.2 and Section 3.3. Immediately after exhausting the food supply, most of the larvae will enter L1 arrest/L1 diapause (Johnson et al., 1984). Some will remain arrested and others will continue on to the dauer stage. Thus, the first dauer larvae do not appear until at least a few days after exhaustion of the food supply. By contrast, very old plates contain relatively fewer dauer larvae. Dauer larva survival decreases with time, whereas the propensity to recover from dauer increases (Klass and Hirsh, 1976; Golden and Riddle, 1984b). In wild-type cultures, there is always a mix of stages observed on the plates. The percentage of dauer larvae versus other stages depends on the conditions listed in Table 2. Dauer larvae also form readily in liquid culture, even in the presence of food (Cassada and Russell, 1975).

Use of starved cultures to generate dauer larvae is the least labor-intensive method of obtaining dauer larvae, as all it requires is a clean plate of worms. This method does not require any special additives or media, and it is scalable simply by setting up more and larger plates. It is also very versatile because dauer larvae of any genotype (except dauer-defective (Daf-d) mutants) will form at any temperature. However, the precise length of time in dauer cannot be controlled with this method, as the history of individual worms on the plate cannot be known. The length of time spent in dauer can impact the biology of the worm (Klass and Hirsh, 1976; Houthoofd et al., 2002; Gomez et al., 2008). Furthermore, because there are other stages beside dauer larvae present in starved cultures, one of the methods to isolate dauer larvae presented in Section 4 must be followed. Fortunately there are several simple, straightforward options to choose from.

\subsubsection{Protocol for dauer induction by starvation}

1. Pick three or more hermaphrodites to a $60 \mathrm{~mm}$ NGM plate (see Maintenance of $C$. elegans) with OP50 or other food source and incubate at the appropriate temperature for your strain. Scale up or down as required.

2. Approximately 10 days later (for healthy, fertile strains grown at $20^{\circ} \mathrm{C}$ ) there should be plenty of dauer larvae on the plate.

See Table 2 for important environmental considerations that will impact dauer formation.

\subsection{Exogenous dauer pheromone}

Adding dauer pheromone to growth medium is a useful method for inducing dauer formation (see Table 1). Individual ascarosides can be added to growth medium to induce dauer formation (Jeong et al., 2005; Butcher et al., 2008). However, these ascarosides must be chemically synthesized and are not currently commercially available. Fortunately, isolating crude dauer pheromone from a liquid culture in which worms have grown is relatively straightforward. Once isolated, pheromone can be stored at $-20^{\circ} \mathrm{C}$ for months to years. It is worth noting that wild C. elegans isolates differ drastically from N2 in their response to different ascarosides, so that adding pheromone derived from N2 may produce a different outcome within a wild isolate (Diaz et al., 2014). Different preparations of dauer pheromone can vary widely in their potency. Some preps can induce Daf-d mutants to enter dauer, even though these mutants will not enter dauer under the conditions found on starved plates (Vowels and Thomas, 1992; Larsen et al., 1995; Ogg et al., 1997). However, many preps that induce penetrant dauer formation in wild-type larvae still fail to induce dauer formation in Daf-d mutants (Golden and Riddle, 1984a). The precise methodology required to produce the stronger prep is unclear.

\subsubsection{Protocols for dauer induction by exogenous pheromone (Zhang et al., 2013; Schroeder and Flatt, 2014)}

There are many protocols for producing crude dauer pheromone that have been published since its discovery in the, 1980s (Golden and Riddle, 1982; Golden and Riddle, 1984a; Golden and Riddle, 1984c; Vowels and Thomas, 1994). Two recent, detailed protocols are recommended above. A video demonstrating their protocol is included in (Schroeder and Flatt, 2014). A detailed protocol for assaying dauer larva formation induced by crude dauer pheromone is also available (Neal et al., 2013). Alternatively, the potency of dauer pheromone can be assayed by testing for inhibition of dauer recovery (Golden and Riddle, 1984c). An outline of the entire process from growing C. elegans cultures to testing the pheromone is shown in Figure 2. See Table 2 for important environmental considerations that will impact dauer formation. In our hands, keeping pheromone plates moist by using freshly poured plates and using a humidified chamber for storage and for experiments increases the penetrance of dauer formation by pheromone (L. Nika and X. Karp, unpublished observations). However, it is not clear that humidity always promotes dauer formation (see Table 2). 
Prepare for liquid culture

-Concentrate bacterial food source

-Grow contamination-free plates of N2 hermaphrodites

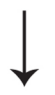

\section{Liquid culture of $C$. elegans}

-Wash worms into $S$ medium in flasks filled to $\sim 1 / 10$ volume

-Add bacterial food source

-Incubate with agitation for 1-2 weeks at the desired temperature

-Supplement cultures with additional food as needed<smiles></smiles>

\section{Extract pheromone from culture medium}

-Pellet worms and retain the supernatant

-Concentrate the supernatant by boiling until a thick brown

residue or a brown crust is obtained

-Extract the residue with ethanol

-Evaporate most of the ethanol

-Filter, and store at $-20^{\circ} \mathrm{C}$

\section{Test dauer pheromone}

-Prepare a modified NGM medium, omitting peptone and adding $50 \mu \mathrm{g} / \mathrm{ml}$ streptomycin to inhibit bacterial growth OR use standard NGM and heat-killed bacteria -Add varying amounts of pheromone to different plates -Add a small amount of concentrated OP50 or other bacteria -Add embryos to plates and test for dauer formation -Choose the concentration that produces the most dauers and the healthiest worms

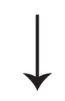

Going forward, pheromone can either be added to pre-made modified NGM plates as described above, or added during the pouring process. In the latter case, it should be added as an additive, at the same time as the salts. In either case, plates stored at $4^{\circ} \mathrm{C}$ should continue to promote dauer formation for at least several weeks, as long as they remain moist.

Figure 2. Summary of dauer pheromone protocols. A flow chart of the major steps involved in isolating crude dauer pheromone, based on protocols discussed in the text.

\subsection{High-density plating}

An alternative to adding dauer pheromone to growth medium is to make use of the pheromone that wild-type worms produce. By plating worms at high density, the pheromone-to-food ratio is high enough to drive larvae into dauer (Hall et al., 2010). A detailed protocol has recently been published (Ow and Hall, 2015). 


\subsubsection{Protocol for dauer induction by high-density growth}

Summarized from Ow and Hall (2015). Note that viewing the original article is recommended for important additional detail and helpful images.

1. Cook egg whites by boiling in $50 \mathrm{~mL}$ water for each egg white, while stirring with a stir bar until the egg white is fully cooked but not burned.

2. Puree the egg white mixture in a kitchen blender until smooth and frothy. Egg white mixture can be used immediately or stored at $4{ }^{\circ} \mathrm{C}$ for $\approx 1$ month or at $-20^{\circ} \mathrm{C}$ indefinitely.

3. Add a thin layer of egg white mixture to the top of several $35 \mathrm{~mm}$ NGM plates (Maintenance of C. elegans) previously seeded with OP50, covering the top of the plates completely. These are "egg white plates".

4. Obtain a well-fed, dense population that includes many gravid adult hermaphrodites growing on $\geq 4100 \mathrm{~mm}$ plates.

5. Wash the above population off the plates, pellet, and add worms to one or more $35 \mathrm{~mm}$ egg white plates.

6. Ensure adequate oxygenation of the worms on the egg white plate by increasing the space between the lid and the plate by adding a small piece of bench tape to the edge of the lid.

7. Incubate the population for $60-72$ hours at $20^{\circ} \mathrm{C}$ or $25^{\circ} \mathrm{C}$. Wild-type strains will enter dauer efficiently at 20 ${ }^{\circ} \mathrm{C}$ under these conditions, but $25{ }^{\circ} \mathrm{C}$ is recommended for strains that enter dauer less readily.

8. A synchronous population of dauer larvae will now be present, together with other stages representing larvae that did not enter dauer. Dauer larvae must be isolated by one of the methods described in Section 4. A detailed protocol to isolate dauer larvae from egg white plates using SDS-resistance and sucrose floatation is available (Ow and Hall, 2015).

\subsection{High temperature}

At high temperature $\left(27^{\circ} \mathrm{C}\right)$ a small proportion of wild-type larvae will enter dauer (Ailion and Thomas, 2000). Larvae with a weak Daf-c mutation often enter dauer at higher penetrance at $27{ }^{\circ} \mathrm{C}$ than at $25^{\circ} \mathrm{C}$, making this a useful technique to study these mutations. However, it should be noted that the genetic pathways regulating dauer formation appear to be modulated at this temperature, such that some genes promote dauer formation at $27^{\circ} \mathrm{C}$ but not $25^{\circ} \mathrm{C}$. For example, loss-of-function mutations in $d a f-3$, encoding the SMAD transcription factor downstream of TGF $\beta$ signaling, cause a Daf-d phenotype at $25{ }^{\circ} \mathrm{C}$, but a Daf-c phenotype at $27{ }^{\circ} \mathrm{C}$ (Ailion and Thomas, 2000). Chemosensory mutants are also Daf-d at $25^{\circ} \mathrm{C}$ (Vowels and Thomas, 1992; Thomas et al., 1993), but Daf-c at $27^{\circ} \mathrm{C}$ (Apfeld and Kenyon, 1999; Ailion and Thomas, 2000). Also, wild-type larvae appear to be on the threshold of the dauer/continuous decision, such that slight variations in environmental conditions can alter this decision (Ailion and Thomas, 2000). Furthermore, dauer larvae formed at $27^{\circ} \mathrm{C}$ can be transient, such that they spontaneously recover from dauer and resume development. Finally, worms are generally unhealthy at this temperature, and larval arrest that is not dauer formation is also observed (Ailion and Thomas, 2000).

\subsubsection{Protocol for dauer induction by temperature (adapted from Ailion and Thomas, 2000)}

1. Pick gravid adults onto a fresh NGM plate (Maintenance of C. elegans) seeded with OP50 or your bacterial strain of choice.

2. Allow the adults to lay eggs for several hours at the temperature at which they normally are maintained.

3. Remove the adults.

4. Shift the plates to $27^{\circ} \mathrm{C}$.

5. $\approx 44$ hours later dauer larvae will have formed (at later time points some larvae may have already recovered from dauer). 


\subsection{Daf-c mutants}

Loss-of-function mutations in dauer-opposing genes result in Daf-c phenotypes. Because wild-type larvae enter dauer more readily at higher temperatures, most Daf-c mutations are temperature-sensitive, providing a convenient method for manipulating dauer formation (Swanson and Riddle, 1981).

\subsection{1. daf-7.}

daf-7(e1372) is a hypomorphic allele that causes penetrant dauer formation at $25^{\circ} \mathrm{C}$. Some dauer larvae can be seen at $20^{\circ} \mathrm{C}$ and even $15{ }^{\circ} \mathrm{C}$, and it is likely that even the larvae that do not enter dauer at the permissive temperatures still grow through L2d (Swanson and Riddle, 1981; Vowels and Thomas, 1992). Thus, strains containing daf-7(e1372) are not suitable for studying the continuous, non-dauer (L1-L2-L3-L4) life history.

daf-7 encodes a TGF $\beta$ protein normally expressed in favorable conditions (Schackwitz et al., 1996; Ren et al., 1996). Lowering daf-7 expression permits activation of the downstream DAF-3/DAF-5 complex (Patterson et al., 1997; da Graca et al., 2004). Crosstalk between pathways then results in modulation of the insulin-like and nuclear hormone receptor pathways (Gerisch et al., 2001; Narasimhan et al., 2011). Perhaps for this reason, daf-7(e1372) dauer larvae appear grossly similar to wild-type dauer larvae. However, daf-7(e1372) mutants do differ from wild-type in the following ways. First, daf-7 dauer larvae live longer than N2 dauer larvae (Banfield et al., 2008). Second, daf-7(e1372) can be used to force dauer formation in Daf-d mutant backgrounds in the insulin-like pathway, even though these Daf-d mutants fail to form dauers on starved plates (Vowels and Thomas, 1992; Larsen et al., 1995). Additionally, daf-7(e1372) mutants are partially defective in recovery from dauer. While $100 \%$ of daf-7(e1372) larvae enter dauer at $25{ }^{\circ} \mathrm{C}$, dauer larvae do not always recover upon shifting to $15{ }^{\circ} \mathrm{C}$. Those that do recover do so asynchronously and over longer timescales than wild-type dauer larvae. This makes daf-7(e1372) less convenient for studying post-dauer stages (see Section 5.2). Finally, daf-7 hermaphrodites have an egg-laying defective (Egl) phenotype, whether or not larvae develop through dauer (Trent et al., 1983).

\subsection{2. daf-2.}

A second gene used to manipulate dauer formation is $d a f-2$, encoding the C. elegans insulin receptor (Kimura et al., 1997). Myriad daf-2 alleles exist, grouped into two classes, where Class II alleles are the more severe and pleiotropic (Gems et al., 1998). The canonical allele, daf-2(e1370), is a Class II allele that is the most commonly used as a tool to induce dauer formation. daf-2(e1370) is similar to daf-7(e1372) in a number of ways: 1) $\approx 100 \%$ of daf-2(e1370) larvae enter dauer at $25^{\circ} \mathrm{C}$ (Gems et al., 1998); 2) daf-2(e1370) can be used to force dauer formation in Daf-d backgrounds, in this case, the TGF $\beta$ pathway (Vowels and Thomas, 1992; Larsen et al., 1995; Ogg et al., 1997); 3) daf-2(e1370) dauer larvae do not all recover from dauer when shifted to $15^{\circ} \mathrm{C}$, and those that do recover do so asynchronously; and 4) daf-2 dauer larvae live longer than wild-type dauer larvae, although the allele examined was $m 41$, not $e 1370$ (Banfield et al., 2008).

daf-2(e1370) also exhibits some differences from daf-7(e1372). There is less dauer formation at $20{ }^{\circ} \mathrm{C}$ and 15 ${ }^{\circ} \mathrm{C}$ (depending on conditions in Table 2). However, non-dauer larvae may still develop through L2d. daf-2(e1370) adult hermaphrodites are not Egl. Additionally, daf-2(e1370) larvae grow slowly at all temperatures, whether or not they enter dauer (Ruaud et al., 2011).

Other $d a f-2$ alleles may also be used to induce dauer formation. These alleles share some features with $e 1370$, but may be different in some regards. For example, some Class I alleles form transient dauers (Gems et al., 1998). Many daf-2 mutants, including e1370, display other pleiotropic phenotypes such as non-dauer larval arrest and extreme longevity (Kenyon et al., 1993; Gems et al., 1998).

\subsubsection{Other alleles.}

Genes from the other dauer pathways are rarely used as tools to induce dauer formation because they are more difficult to work with and/or defective in various aspects of dauer morphogenesis (Albert and Riddle, 1988; Vowels and Thomas, 1994; Antebi et al., 1998).

\subsubsection{Protocol for dauer induction by Daf-c mutations}

1. Allow gravid adult hermaphrodites to lay eggs for several hours on standard plates* (Maintenance of $C$. elegans) 
2. Remove adults if a synchronous population is desired.

3. Incubate progeny at $25^{\circ} \mathrm{C}$ to induce dauer formation.

4. Dauer larvae will form by approximately 48 hours at $25^{\circ} \mathrm{C}$ for $d a f-7(e 1372)^{\dagger}$ and by approximately 80 hours at $25^{\circ} \mathrm{C}$ for $d a f-2(e 1370)$.

*If Daf-c alleles are used that cause transient dauer arrest, a short egg-lay with more gravid adult hermaphrodites per plate is advisable. For larger scale experiments embryos can be isolated by egg prep/bleaching protocols. Care should be used in deciding whether to further synchronize larvae by hatching the embryos in the absence of food. Larvae that experience L1 arrest have altered biology and gene expression, and are less likely to enter dauer than those that have not been arrested (Golden and Riddle, 1984b; Johnson et al., 1984; Baugh et al., 2009; Karp et al., 2011).

${ }^{\dagger}$ Note that $d a f-7(e 1372)$ is somewhat Egl, leading to a less synchronous population than in wild-type.

\section{Isolating dauer larvae}

Dauer larvae can be isolated from other stages by virtue of the unique features of dauer larvae, discussed below. Two methods, SDS selection and fluorescent beads, take advantage of these features to allow rapid isolation of large numbers of dauer larvae (Section 4.1 and Section 4.2). In addition to these methods, other unique dauer features can be helpful in identifying individual dauer larvae in different contexts (Sections 4.3 and Section 4.4). Figure 3 summarizes three useful characteristics for identifying dauer larvae with respect to developmental progression through the dauer life history.

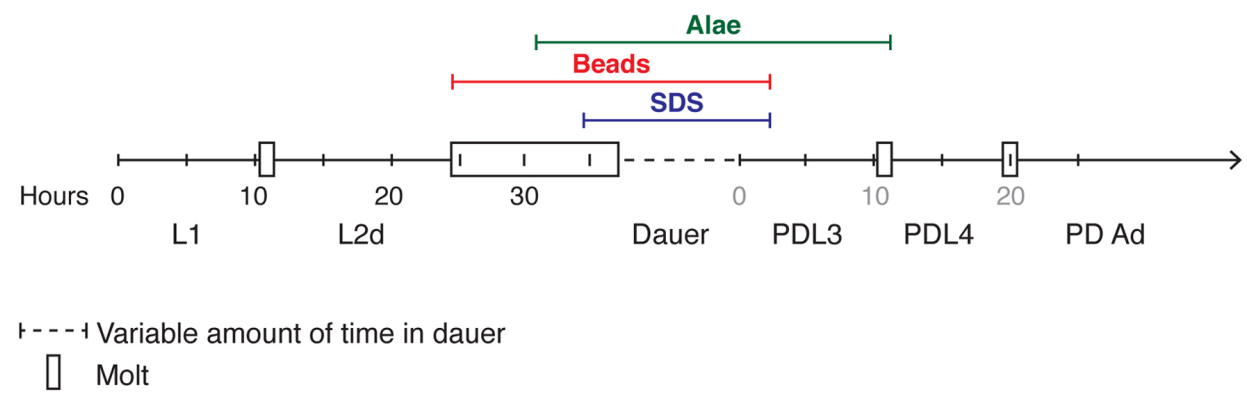

Figure 3. Developmental timeline in the dauer life history. Developmental stages are shown approximately to scale with chronological time for wild-type (N2) hermaphrodites at $25{ }^{\circ} \mathrm{C}$ (Cassada and Russell, 1975; Golden and Riddle, 1984b; Reape and Burnell, 1990). Black numbers indicate the hours after hatching whereas grey numbers indicate the hours after stimulation of dauer larvae to recover. It should be noted that the length of L2d can vary depending on the strength of dauer-inducing conditions (Golden and Riddle, 1984b). Three methods useful for isolating dauer larvae are shown, indicating the developmental stages they encompass. See text for more details.

\subsection{SDS selection}

The most commonly used technique to isolate dauer larvae is selection with $1 \%$ sodium dodecyl sulfate (SDS). SDS resistance is based on the presence of both a thickened cuticle and a buccal plug, effectively insulating dauer larvae from the environment (Cassada and Russell, 1975). These features are established during the L2d-dauer molt (Golden and Riddle, 1984b). If dauer larvae are stimulated to recover, they lose the buccal plug and become sensitive to SDS within a few hours. However, they retain the dauer cuticle until they molt into the post-dauer L4 stage, approximately 16-20 hours after recovery is initiated at $20{ }^{\circ} \mathrm{C}$ (Cassada and Russell, 1975). Embryos are partially SDS-resistant, but embryos are easily distinguished from dauer larvae and are not present in starved cultures (Cassada and Russell, 1975).

\subsubsection{SDS protocol, for large numbers of dauer larvae}

1. Wash worms off plates, pellet, and resuspend in $1 \%$ SDS.

2. Incubate worms in $1 \%$ SDS for 30 minutes* with gentle agitation. 
3. Wash dauer larvae 1-5 times with water to remove all SDS.

4. At this point, the tube will contain living dauer larvae and the carcasses of non-dauer larvae. If it is necessary to remove the carcasses, perform a sucrose floatation step (Epstein and Shakes, 1995).

*30 minutes is the standard time used; however, 10 minutes is sufficient to kill wild-type non-dauer stages, including recovering dauer larvae (Cassada and Russell, 1975; Nika et al., 2016). Wild-type dauer larvae can remain in SDS for hours.

\subsubsection{SDS protocol, for small numbers of dauer larvae}

If you have very few worms that you need to test and do not want to risk losing them in a wash, this protocol may be more suitable.

1. Pipette $\approx 1 \mathrm{ml} 1 \%$ SDS into an empty $35 \mathrm{~mm}$ Petri dish.

2. Pick worms into the SDS.

3. Incubate worms in $1 \%$ SDS for 30 minutes* with gentle agitation.

4. Use an eyebrow pick to retrieve the worms.

5. As an alternative to the eyebrow pick, use a sterile micropipette or Pasteur pipet to transfer the worms and SDS to an NGM plate (Maintenance of $C$. elegans). The larvae must then be picked to a fresh plate before the SDS begins to dry, because SDS crystals make it difficult to visualize the worms.

*30 minutes is the standard time used; however, 10 minutes is sufficient to kill wild-type non-dauer stages, including recovering dauer larvae (Cassada and Russell, 1975; Nika et al., 2016). Wild-type dauer larvae can remain in SDS for hours (Cassada and Russell, 1975).

\subsection{Fluorescent beads}

An alternative to SDS-selection that is particularly useful for SDS-sensitive mutants or for quantitative analyses is the use of fluorescent latex beads mixed into the bacterial food source. Dauer larvae neither eat nor pump, consistent with the presence of the buccal plug, and therefore lack beads in their digestive tract (Cassada and Russell, 1975; Nika et al., 2016). Indeed, the intestines of L2d larvae are emptied upon entering the L2d-dauer molt, and they remain empty until a few hours after recovery is initiated (Nika et al., 2016). Other stages, with the exception of molting larvae, do contain beads in their digestive tract. If starved cultures are used to induce dauer formation, no molting larvae are present and lack of beads is highly effective to identify dauer larvae. Beads can also be used to isolate dauer larvae induced by other methods (Nika et al., 2016).

The presence or absence of beads can be visualized using a fluorescence dissecting microscope (Nika et al., 2016). GFP-labeled OP50 can be used as an alternative to beads, but are harder to visualize (Nika et al., 2016).

\subsubsection{Bead protocol for isolating dauer larvae from starved plates}

1. Culture OP50 or the bacterial strain of your choice overnight, and concentrate the culture 10X (by spinning and resuspending the pellet in $1 / 10$ the culture volume).

2. Add $1 \mu \mathrm{L}$ of fluorescent beads (Sigma L3280; $0.5 \mu \mathrm{m}$, red fluorescence) to each $1 \mathrm{~mL}$ of concentrated OP50 to produce a ratio of $1: 1000(\mathrm{v} / \mathrm{v})$ beads to bacteria.

3. Add $65 \mu \mathrm{l}$ of the bead-food mixture to a $60 \mathrm{~mm}$ NGM plate (Maintenance of C. elegans) and allow to dry (plates can be prepared in advance and stored at $4{ }^{\circ} \mathrm{C}$ for up to 8 weeks).

4. Wash worms from starved cultures, pellet, and add to the prepared NGM+beads+OP50 plate.

5. Incubate at least 20 minutes and no longer than 90 minutes at $20^{\circ} \mathrm{C}$. 
6. Use a fluorescence dissecting microscope with a DS-Red filter at 100X magnification (or a Rhodamine filter at 150X magnification) to pick out worms that lack beads: these are dauer larvae.

\subsubsection{Bead protocol for isolating dauer larvae formed by exogenous pheromone or Daf-c mutation}

\section{1-3. Complete steps 1-3 from the protocol above.}

1. Add embryos to plates and incubate at $25^{\circ} \mathrm{C}$.

2. After $\approx 55$ hours use a fluorescence dissecting microscope with a DS-Red filter at $100 \mathrm{X}$ magnification (or a Rhodamine filter at 150X magnifictation) to pick out worms that lack beads: these are dauer larvae.

Note that beads are also effective at isolating mutant larvae with incomplete dauer morphogenesis (also called "partial dauer" or "dauer-like" larvae) formed by Daf mutants, such as daf-16; daf-7 (Nika et al., 2016). In this strain, beads are not efficiently excreted prior to molting into dauer. Therefore, the best way to isolate dauer larvae is to grow larvae in the absence of beads at $25{ }^{\circ} \mathrm{C}$ to stimulate dauer formation, and then transfer larvae to bead-containing plates for 30 minutes. Larvae in the dauer stage will lack beads. This method is recommended over SDS-selection because daf-16; daf-7 larvae display some SDS sensitivity (Nika et al., 2016). Other partial dauer mutants have not been tested, but may be similar to daf-16; daf-7.

\subsection{Dauer morphology}

\subsubsection{Dauer alae}

The most unambiguous morphological criterion that distinguishes dauer larvae is the presence of dauer alae on the cuticle (Rossi et al., 2012) (Figure 4). Dauer alae form during the molt into dauer and remain until post-dauer larvae molt into the PDL4 stage (Figure 3) (Cassada and Russell, 1975). However, after recovery, during the PDL3 stage, dauer alae become stretched and more difficult to see as the larvae lose radial constriction (Riddle et al., 1997). A compound microscope is required to visualize dauer alae, and thus using dauer alae to identify dauer larvae is not recommended for high throughput applications. 

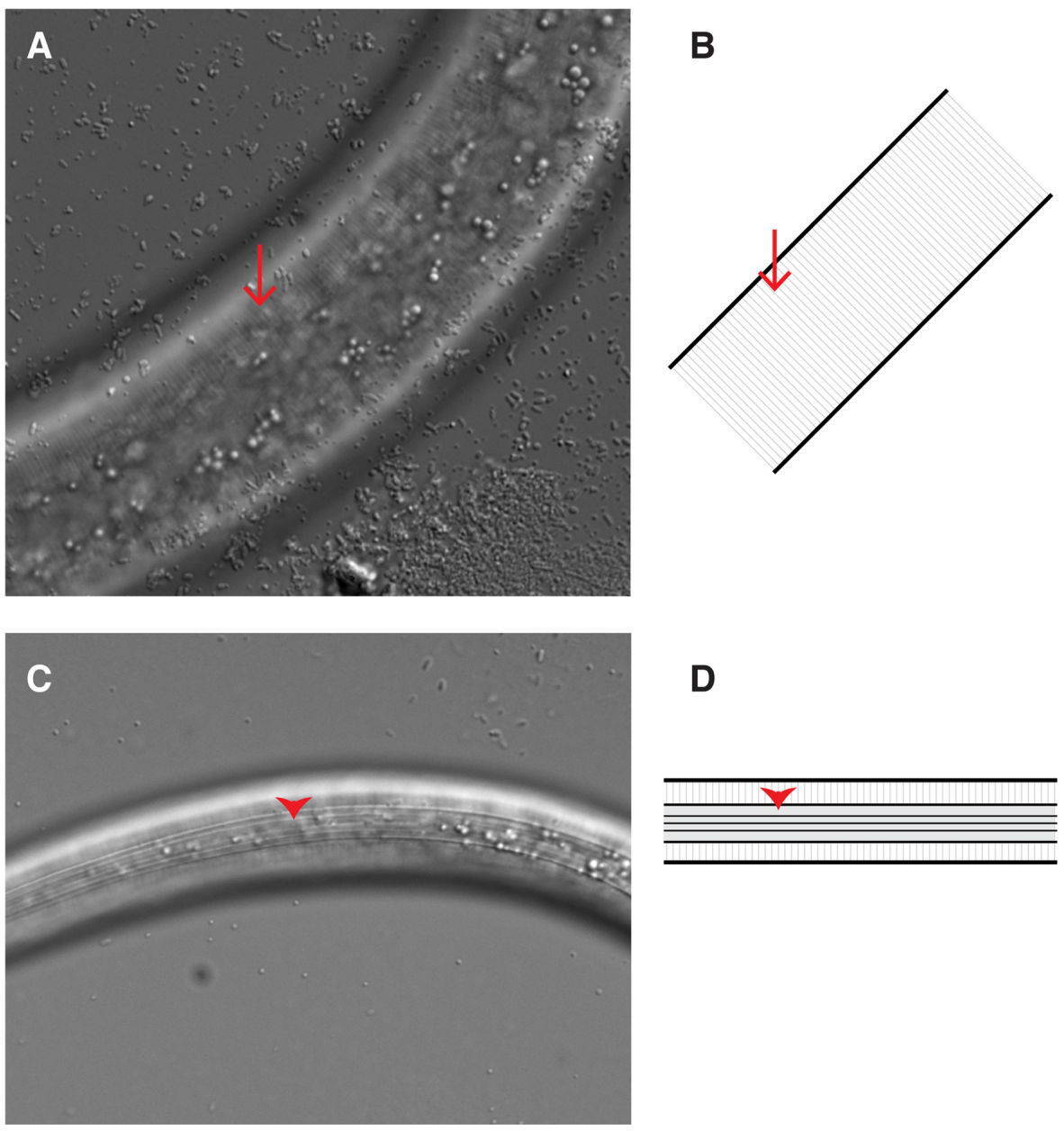

D

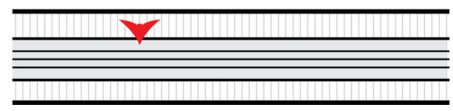

Figure 4. Cuticles of L3 and dauer larvae. (A, B) The lateral cuticle of an L3-staged larva imaged with DIC optics (A), or diagrammed (B). Annulae (arrows) are faintly apparent as ridges running perpendicular to the anterior-posterior axis. (C, D) The lateral cuticle of a dauer larva imaged with DIC optics (C), or diagrammed (D). Broad dauer alae (arrowheads) are clearly visible running parallel to the anterior-posterior axis. DIC images were taken at the identical magnification (630X), highlighting the radial constriction of the dauer larva. Anterior is to the left.

\subsubsection{Radial constriction}

The bodies of dauer larvae are highly constricted, such that dauer larvae appear longer and skinnier than other stages when viewed under the dissecting microscope. They also tend to appear darker, due to an increase in fat stores (Cassada and Russell, 1975). When examined more closely under the compound microscope, it can be seen that the pharynx is particularly constricted. Constriction initiates during the L2d to dauer molt (Golden and Riddle, 1984b). During recovery restriction decreases, such that larvae are noticeably less constricted after $\approx 12$ hours of recovery (Cassada and Russell, 1975). When looking at a large population, unambiguous identification of dauer larvae based on radial constriction is more difficult than the preceding methods. This is particularly true when the population is starved, because non-dauer animals are often skinny.

\subsubsection{Refractile bodies}

The hypodermis and the intestine of dauer larvae both appear dark when viewed under the dissecting microscope, due to the accumulation of refractile granules in these tissues (Vowels and Thomas, 1992). On a slide, these tissues appear bright by DIC and autofluorescent under UV light. This feature is more characteristic of the dauer life history than the dauer stage per se, because granules begin accumulating during L2d (Golden and Riddle, 1984b) and persist in post-dauer stages (X. Karp, unpublished observations). 


\subsection{Other dauer characteristics}

Several additional features of dauer larvae have been observed. More investment is generally required to use these features compared to those described above because specialized markers, equipment, and/or experience are needed.

\subsubsection{Behavior}

Dauer larvae display several behaviors that distinguish them from other stages. First, dauer larvae can nictate, or stand on their tails and wave back and forth. Nictation is thought to be a dispersal behavior unique to dauer larvae. Nictation cannot occur without a substrate such as mold or gauze and thus will not occur on standard, uncontaminated plates (Cassada and Russell, 1975; Lee et al., 2012). Dauer larvae on the surface of a plate are often quiescent, and can appear still and rodlike. They do however move quickly in response to stimuli (Cassada and Russell, 1975; Lee et al., 2012).

\subsubsection{IL2 Neurons:}

IL2 sensory neurons, found in the head, display two dauer characteristics. First, a lag-2::GFP reporter is expressed in IL2 neurons throughout the dauer stage, but not during other stages (Ouellet et al., 2008). Second, IL2 neurons undergo dauer-specific dendritic arborization, visualizable with lag-2::GFP or klp-6::GFP (Schroeder et al., 2013).

\subsubsection{Excretory duct pulsation}

The gland cell of dauer larvae lacks visible secretory granules, and the excretory duct of dauer larvae pulses at a frequency dependent on osmotic conditions (Nelson et al., 1983; Nelson and Riddle, 1984). This pulsation can be viewed by DIC optics, if dauer larvae are not anesthetized (Nelson and Riddle, 1984).

\section{Pre- and post-dauer stages}

In addition to isolating dauer larvae, pre- and post-dauer larvae can be isolated and studied. Dauer is induced using one of the methods described in Section 2 (see Table 1 for information about which methods are useful for isolating pre- or post-dauer larvae).

\subsection{Pre-dauer larvae}

The pre-dauer L2d stage is different in many respects from the L2 stage. First, it is at least $50 \%$ longer than the L2 stage. During this time, larvae assess their environmental conditions and prepare for dauer formation, including accumulating fat stores (Golden and Riddle, 1984b). Gene expression is also somewhat different in L2d larvae compared to L2 larvae (Liu et al., 2004; Harvey et al., 2009; Jeong et al., 2009; Karp et al., 2011). The lethargus and molt between L2d and dauer is also unique. It lasts approximately 12 hours at $25{ }^{\circ} \mathrm{C}$, in contrast to the 1-2hr molting period between all other stages (Golden and Riddle, 1984b).

\subsubsection{Obtaining pre-dauer larvae}

L2d larvae can be recognized by their darkened appearance and by the length of time in the second larval stage (Golden and Riddle, 1984b). However, neither of these traits is sufficient to pick them out of a mixed population of worms. No L2d-specific fluorescent markers have been characterized. The best way to obtain L2d larvae, therefore, is to start with a synchronized population of embryos and grow the larvae in dauer-inducing conditions such as dauer pheromone or using a Daf-c mutation (see Table 1). Larvae grown under such conditions for approximately $24-30$ hours after egg-laying $\left(25^{\circ} \mathrm{C}\right)$ will be in the L2d stage (Figure 3).

\subsection{Post-dauer larvae and adults}

When wild-type dauer larvae are placed in favorable environmental conditions, they will recover quickly and synchronously. The first signs of recovery are pumping and feeding, beginning within two hours at $20^{\circ} \mathrm{C}$ (Cassada and Russell, 1975; Nika et al., 2016). Over the next several hours recovering dauer larvae feed, lose their radial constriction, and adjust their metabolism back to a non-dauer state. Gene expression also changes during this time (Wang and Kim, 2003). By $\approx 10-12$ hours after stimulation to recovery at $20^{\circ} \mathrm{C}$, or $\approx 7-8$ hours at $25^{\circ} \mathrm{C}$, they reach 
the PDL3 (post-dauer L3 stage), where cell division and development have resumed. Cell fates, including cell divisions and expression of cell fate markers, are equivalent between L3 and PDL3 stages (Liu and Ambros, 1991; Euling and Ambros, 1996; Braendle and Félix, 2008; Karp and Greenwald, 2013). However, no molt occurs between dauer and PDL3. Thus, dauer alae are still visible on the cuticle, although more difficult to see because they become stretched as the larva loses radial constriction and begins to grow (Cassada and Russell, 1975; Riddle et al., 1997).

Larvae molt from PDL3 to the PDL4 stage approximately 16 hours after stimulation to recover from dauer at $20{ }^{\circ} \mathrm{C}$, or 12 hours after stimulation to recover at $25^{\circ} \mathrm{C}$ (Figure 3) (Cassada and Russell, 1975; Reape and Burnell, 1990). PDL4 larvae are morphologically indistinguishable from L4 larvae, at least at the gross level. Similarly, PD adults appear identical to adults that developed continuously. However, subtle differences do exist. For example, some changes in muscle arm and neuronal cell structure persist in post-dauer stages (Dixon et al., 2008; Schroeder et al., 2013). Interestingly, this apparent similarity between post-dauer and continuously developed animals belies a number of changes at the level of expression of protein coding and small RNA coding genes, as well as changes in chromatin structure (Hall et al., 2010; Karp et al., 2011; Hall et al., 2013).

\subsubsection{Obtaining wild-type post-dauer larvae and adults}

Aside from the presence of dauer alae on PDL3 staged larvae, no simple morphological marker exists to distinguish PD animals from those that developed continuously. The best way to study post-dauer animals is to start with a population of dauer larvae isolated using one of the methods in Section 4, and allow them to recover (Figure 3) (Cassada and Russell, 1975). Larvae become committed to recovery within one hour, but the first signs of recovery (resumption of pumping and feeding) are not apparent for another 1-2 hours (Cassada and Russell, 1975; Nika et al., 2016). Depending on the experiment, it may or may not be important to control the length of time larvae spent in dauer prior to recovery (see Table 1). It is worth noting that the propensity of dauer larvae to recover increases over time (Golden and Riddle, 1984b). However, over several weeks, the ability of dauer larvae to recover decreases (Klass and Hirsh, 1976).

\subsubsection{Protocol for isolating wild-type PD worms}

1. Use a method from Section 3 to obtain dauer larvae.

2. SDS select (Section 4.1; it is not necessary to remove carcasses) or use fluorescent beads (Section 4.2) to isolate dauer larvae.

3. Place dauer larvae on a fresh NGM plate (Maintenance of C. elegans) with a bacterial food source and incubate at the desired temperature $\left(15^{\circ} \mathrm{C}-25^{\circ} \mathrm{C}\right)$.

4. To identify recovering dauer larvae, fluorescent beads should be added to the food source (Section 4.2). Within 2 hours of recovery at $20^{\circ} \mathrm{C}$, beads will be present in the digestive tract of a few larvae, indicating they have lost their buccal plug and begun to feed. By 3 hours, nearly 100\% of larvae will be feeding (Nika et al., 2016).

5. To identify post-dauer L3-staged larvae, allow larvae to recover $\approx 14$ hours at $20{ }^{\circ} \mathrm{C}\left(\sim 8\right.$ hours at $\left.25{ }^{\circ} \mathrm{C}\right)$. Staging can be verified by the presence of indistinct dauer alae on the cuticle and by gonad and vulval morphology equivalent to L3-staged continuously developing larvae (Euling and Ambros, 1996).

6. To identify later stages, standard anatomical criteria can be used. See Ow and Hall (2015) for details about obtaining post-dauer adults, and for details about obtaining a synchronous control population of adults that did not experience dauer.

\subsubsection{Obtaining Daf-c post-dauer larvae and adults}

Daf-c mutants recover asynchronously, and therefore allowing them to recover for certain periods of time is less helpful in obtaining particular stages. Post-dauer L4 and adult stages are easily recognized by their increased body size and by the development of their tissues, particularly the somatic gonad, germline, and vulva. However, distinguishing the early stages of recovery/post-dauer L3 can be challenging. The simplest way to accomplish this is by using fluorescent latex beads, as described in Section 4.2. Larvae that are still within dauer lack beads whereas recovering larvae will have begun feeding and thus will have beads in their digestive tract. This method is also effective for distinguishing dauer and recovering mutant partial dauer larvae (Nika et al., 2016). Using beads rather than SDS to isolate dauer larvae is recommended for dauer-like larvae that may exhibit some SDS sensitivity (Nika et al. 2016). 


\subsubsection{Protocol for isolating PD Daf-c worms}

1. Culture OP50 or the bacterial strain of your choice overnight, and concentrate the culture 10X (by spinning and resuspending the pellet in $1 / 10$ the culture volume).

2. Add $1 \mu \mathrm{L}$ of fluorescent beads (Sigma L3280; $0.5 \mu \mathrm{m}$, red fluorescence) to each $1 \mathrm{ml}$ of concentrated OP50 to produce a ratio of $1: 1000(\mathrm{v} / \mathrm{v})$ beads to bacteria.

3. Add $65 \mu \mathrm{l}$ of the bead-food mixture to a $60 \mathrm{~mm} \mathrm{NGM}$ plate (Maintenance of $C$. elegans) and allow to dry (plates can be prepared in advance and stored at $4{ }^{\circ} \mathrm{C}$ ).

4. Use these plates when inducing dauer formation in a Daf-c background (Section 3.5). Beads will be removed from the intestine prior to the L2d-dauer molt, and thus dauer larvae will lack beads* (Nika et al., 2016).

5. Alternatively, induce dauer formation on standard plates, and then pick dauer larvae to bead-containing plates.

6. Shift dauer larvae to $15^{\circ} \mathrm{C}$.

7. Monitor for recovery by using a fluorescence microscope with a DS-Red filter at 100X magnification (or a Rhodamine filter at $150 \mathrm{X}$ magnification) to look for beads within the digestive tract.

8. Recovery takes significantly longer than in wild-type. Typically, we see that about half the population has recovered 24 hours after shifting to $15^{\circ} \mathrm{C}$, but wide variation is observed. We find that the longer a Daf-c mutant dauer larva is kept at $25^{\circ} \mathrm{C}$, the more difficult recovery is (unpublished).

* daf-16; daf-7 dauer-like larvae, and potentially other dauer-like larvae do not all expel beads as they molt into dauer. Therefore, these larvae should be grown on standard plates until dauer formation, and then moved to bead-containing plates (Nika et al., 2016).

\section{Acknowledgements}

Many thanks to Sarah Hall (Syracuse University) for sharing the high density plating protocol prior to publication, and to Scott Neal (Brandeis University) helpful discussions. Thanks to Eric Montoye (Central Michigan University) for micrographs of dauer larvae. Thanks to Claudia Tenen (Columbia University) and to members of the Karp lab for comments on the manuscript. XK is supported by a grant from the National Institutes of Health (R15 GM1 17568) and by a grant from Central Michigan University (C62241).

\section{References}

Ailion M., and Thomas J.H. (2000). Dauer formation induced by high temperatures in Caenorhabditis elegans. Genetics 156, 1047-1067. Abstract Article

Albert P.S., and Riddle D.L. (1988). Mutants of Caenorhabditis elegans that form dauer-like larvae. Dev. Biol. 126, 270-293. Abstract Article

Antebi A. Nuclear receptor signal transduction in C. elegans (June 9, 2015), WormBook, ed. The C. elegans Research Community, WormBook, doi/10.1895/wormbook.1.64.2,www.wormbook.org. Abstract Article

Antebi A., Culotti J.G., and Hedgecock E.M. (1998). daf-12 regulates developmental age and the dauer alternative in Caenorhabditis elegans. Development 125, 1191-1205. Abstract Article

Apfeld J., and Kenyon C. (1999). Regulation of lifespan by sensory perception in Caenorhabditis elegans. Nature 402, 804-809. Abstract Article

Banfield K.L., Gomez T.A., Lee W., Clarke S., and Larsen P.L. (2008). Protein-repair and hormone-signaling pathways specify dauer and adult longevity and dauer development in Caenorhabditis elegans. J. Gerontol. A Biol. Sci. Med. Sci. 63, 798-808. Abstract Article 
Barrière A., and Félix M.-A. (2005). High local genetic diversity and low outcrossing rate in Caenorhabditis elegans natural populations. Curr. Biol. 15, 1176-1184. Abstract Article

Baugh L.R., Demodena J., and Sternberg P.W. (2009). RNA Pol II accumulates at promoters of growth genes during developmental arrest. Science 324, 92-94. Abstract Article

Braendle C., and Félix M.-A. (2008). Plasticity and errors of a robust developmental system in different environments. Dev. Cell 15, 714-724. Abstract Article

Butcher R.A., Ragains J.R., Kim E., and Clardy J. (2008). A potent dauer pheromone component in Caenorhabditis elegans that acts synergistically with other components. Proc. Natl. Acad. Sci. U. S. A. 105, 14288-14292. Abstract Article

Cassada R.C., and Russell R.L. (1975). The dauerlarva, a post-embryonic developmental variant of the nematode Caenorhabditis elegans. Dev. Biol. 46, 326-342. Abstract Article

da Graca L.S., Zimmerman K.K., Mitchell M.C., Kozhan-Gorodetska M., Sekiewicz K., Morales Y., and Patterson G.I. (2004). DAF-5 is a Ski oncoprotein homolog that functions in a neuronal TGF $\beta$ pathway to regulate $C$. elegans dauer development. Development 131, 435-446. Abstract Article

Diaz S.A., Brunet V., Lloyd-Jones G.C., Spinner W., Wharam B., and Viney M. (2014). Diverse and potentially manipulative signalling with ascarosides in the model nematode C. elegans. BMC Evol. Biol. 14, 46. Abstract Article

Dixon S.J., Alexander M., Chan K.K.M., and Roy P.J. (2008). Insulin-like signaling negatively regulates muscle arm extension through DAF-12 in Caenorhabditis elegans. Dev. Biol. 318, 153-161. Abstract Article

Epstein H.F., and Shakes D.C., Eds. (1995). Caenorhabditis elegans: Modern Biological Analysis of an Organism. (San Diego: Academic Press).

Euling S., and Ambros V. (1996). Reversal of cell fate determination in Caenorhabditis elegans vulval development. Development 122, 2507-2515. Abstract Article

Fielenbach N., and Antebi A. (2008). C. elegans dauer formation and the molecular basis of plasticity. Genes Dev. 22, 2149-2165. Abstract Article

Gems D., Sutton A.J., Sundermeyer M.L., Albert P.S., King K.V., Edgley M.L., Larsen P.L., and Riddle D.L. (1998). Two pleiotropic classes of daf-2 mutation affect larval arrest, adult behavior, reproduction and longevity in Caenorhabditis elegans. Genetics 150, 129-155. Abstract Article

Gerisch B., Weitzel C., Kober-Eisermann C., Rottiers V., and Antebi A. (2001). A hormonal signaling pathway influencing $C$. elegans metabolism, reproductive development, and life span. Deve. Cell 1, 841-851. Abstract Article

Golden J.W., and Riddle D.L. (1982). A pheromone influences larval development in the nematode Caenorhabditis elegans. Science 218, 578-580. Abstract Article

Golden J.W., and Riddle D.L., (1984a). A pheromone-induced developmental switch in Caenorhabditis elegans: Temperature-sensitive mutants reveal a wild-type temperature-dependent process. Proc. Natl. Acad. Sci. U. S. A. 81, 819-823. Abstract Article

Golden J.W., and Riddle D.L., (1984b). The Caenorhabditis elegans dauer larva: developmental effects of pheromone, food, and temperature. Dev. Biol. 102, 368-378. Abstract Article

Golden J.W., and Riddle D.L., (1984c). A Caenorhabditis elegans dauer-inducing pheromone and an antagonistic component of the food supply. J. Chem. Ecol. 10, 1265-1280. Abstract Article

Gomez T.A., Banfield K.L., and Clarke S.G. (2008). The protein L-isoaspartyl-O-methyltransferase functions in the Caenorhabditis elegans stress response. Mech. Ageing Dev. 129, 752-758. Abstract Article 
Gumienny T.L., Savage-Dunn C. TGF- $\beta$ signaling in C. elegans (July 10, 2013), WormBook, ed. The C. elegans Research Community, WormBook, doi/10.1895/wormbook.1.22.2,http://www.wormbook.org. Abstract Article

Hall S.E., Beverly M., Russ C., Nusbaum C., and Sengupta P. (2010). A cellular memory of developmental history generates phenotypic diversity in C. elegans. Curr. Biol. 20, 149-155. Abstract Article

Hall S.E., Chirn G.W., Lau N.C., and Sengupta P. (2013). RNAi pathways contribute to developmental history-dependent phenotypic plasticity in C. elegans. RNA 19, 306-319. Abstract Article

Harvey S.C., Barker G.L., Shorto A., and Viney M.E. (2009). Natural variation in gene expression in the early development of dauer larvae of Caenorhabditis elegans. BMC Genomics 10, 325. Abstract Article

Houthoofd K., Braeckman B.P., Lenaerts I., Brys K., De Vreese A., Van Eygen S., and Vanfleteren J.R. (2002). Ageing is reversed, and metabolism is reset to young levels in recovering dauer larvae of C. elegans. Exp. Gerontol. 37, 1015-1021. Abstract Article

Hu P.J. Dauer (August 08, 2007), WormBook, ed. The C. elegans Research Community, WormBook, doi/10.1895/wormbook.1.144.1, http://www.wormbook.org. Abstract Article

Jeong P.-Y., Jung M., Yim Y.-H., Kim H., Park M., Hong E., Lee W., Kim Y.H., Kim K., and Paik Y.-K. (2005). Chemical structure and biological activity of the Caenorhabditis elegans dauer-inducing pheromone. Nature 433, 541-545. Abstract Article

Jeong P.-Y., Kwon M.-S., Joo H.-J., and Paik Y.-K. (2009). Molecular time-course and the metabolic basis of entry into dauer in Caenorhabditis elegans. PLoS One 4, e4162. Abstract Article

Johnson T.E., Mitchell D.H., Kline S., Kemal R., and Foy J. (1984). Arresting development arrests aging in the nematode Caenorhabditis elegans. Mech. Ageing Dev. 28, 23-40. Abstract Article

Kaplan F., Srinivasan J., Mahanti P., Ajredini R., Durak O., Nimalendran R., Sternberg P.W., Teal P.E.A., Schroeder F.C., Edison A.S., and Alborn H.T. (2011). Ascaroside expression in Caenorhabditis elegans is strongly dependent on diet and developmental stage. PLoS One 6, e17804. Abstract Article

Karp X., and Greenwald I. (2013). Control of cell-fate plasticity and maintenance of multipotency by DAF-16/FoxO in quiescent Caenorhabditis elegans. Proc. Natl. Acad. Sci. U. S. A. 110, 2181-2186. Abstract Article

Karp X., Hammell M., Ow M.C., and Ambros V. (2011). Effect of life history on microRNA expression during $C$. elegans development. RNA 17, 639-651. Abstract Article

Kaul T.K., Reis Rodrigues P., Ogungbe I.V., Kapahi P., and Gill M.S. (2014). Bacterial fatty acids enhance recovery from the dauer larva in Caenorhabditis elegans. PLoS One 9, e86979. Abstract Article

Kenyon C., Chang J., Gensch E., Rudner A., and Tabtiang R. (1993). A C. elegans mutant that lives twice as long as wild type. Nature 366, 461-464. Abstract Article

Kimura K. D., Tissenbaum H. A., Liu Y., and Ruvkun G. (1997). daf-2, an insulin receptor-like gene that regulates longevity and diapause in Caenorhabditis elegans. Science 277, 942-946. Abstract Article

Klass M., and Hirsh D. (1976). Non-ageing developmental variant of Caenorhabditis elegans. Nature 260, $523-525$. Abstract Article

Larsen P.L., Albert P.S., and Riddle D.L. (1995). Genes that regulate both development and longevity in Caenorhabditis elegans. Genetics 139, 1567-1583. Abstract Article

Lee H., Choi M.-K., Lee D., Kim H.-S., Hwang H., Kim H., Park S., Paik Y.-K., and Lee J. (2012). Nictation, a dispersal behavior of the nematode Caenorhabditis elegans, is regulated by IL2 neurons. Nat. Neurosci. 15, 107-112. Abstract Article 
Liu T., Zimmerman K.K., and Patterson G.I. (2004). Regulation of signaling genes by TGF $\beta$ during entry into dauer diapause in C. elegans. BMC Dev. Biol. 4, 11. Abstract Article

Liu Z., and Ambros V. (1991). Alternative temporal control systems for hypodermal cell differentiation in Caenorhabditis elegans. Nature 350, 162-165. Abstract Article

Murphy C.T., Hu P.J. Insulin/insulin-like growth factor signaling in C. elegans (December 26, 2013), WormBook, ed. The C. elegans Research Community, WormBook, doi/10.1895/wormbook.1.164.1, http://www.wormbook.org. Abstract Article

Narasimhan S.D., Yen K., Bansal A., Kwon E.-S., Padmanabhan S., and Tissenbaum H.A. (2011). PDP-1 links the TGF- $\beta$ and IIS pathways to regulate longevity, development, and metabolism. PLoS Genet. 7, e1001377. Abstract Article

Neal S.J., Kim K., and Sengupta P. (2013). Quantitative assessment of pheromone-induced dauer formation in Caenorhabditis elegans. Methods Mol. Biol. 1068, 273-283. Abstract Article

Neal S. J., Takeishi A., ODonnell M.P., Park J., Hong M., Butcher R.A., Kim K., and Sengupta P. (2015). Feeding state-dependent regulation of developmental plasticity via CaMKI and neuroendocrine signaling. eLife 4 , e10110. Abstract Article

Nelson F.K., and Riddle D.L. (1984). Functional study of the Caenorhabditis elegans secretory-excretory system using laser microsurgery. J. Exp. Zool. 231, 45-56. Abstract Article

Nelson F.K., Albert P.S., and Riddle D.L. (1983). Fine structure of the Caenorhabditis elegans secretory-excretory system. J. Ultrastruct. Res. 82, 156-171. Abstract Article

Nika L., Gibson T., Konkus R., and Karp X. (2016). Fluorescent beads are a versatile tool for staging Caenorhabditis elegans in different life histories. G3 pii: g3.116.030163. doi:10.1534/g3.116.030163. Abstract Article

Ogg S., Paradis S., Gottlieb S., Patterson G.I., Lee L., Tissenbaum H.A., and Ruvkun G. (1997). The Fork head transcription factor DAF-16 transduces insulin-like metabolic and longevity signals in C. elegans. Nature 389, 994-999. Abstract Article

Ouellet J., Li S., and Roy R. (2008). Notch signalling is required for both dauer maintenance and recovery in $C$. elegans. Development 135, 2583-2592. Abstract Article

Ow M.C., and Hall S.E. (2015). A method for obtaining large populations of synchronized Caenorhabditis elegans dauer larvae. Methods Mol. Biol. 1327, 209-219. Abstract Article

Patterson G.I., Koweek A., Wong A., Liu Y., and Ruvkun G. (1997). The DAF-3 Smad protein antagonizes TGF- $\beta$-related receptor signaling in the Caenorhabditis elegans dauer pathway. Genes Dev. 11, $2679-2690$. Abstract Article

Reape T.J., and Burnell A.M. (1990). Enzyme induction in recovering dauer larvae of the nematode Caenorhabditis elegans in response to increasing concentrations of food source in the recovery medium. Biochem. Biophys. Res. Commun. 172, 1013-1021. Abstract Article

Ren P., Lim C.S., Johnsen R., Albert P.S., Pilgrim D., and Riddle D.L. (1996). Control of C. elegans larval development by neuronal expression of a TGF- $\beta$ homolog. Science 274, 1389-1391. Abstract Article

Riddle D.L., Blumenthal T., Meyer B.J., Priess J.R., and Albert P.S. (1997). Genetic and Environmental Regulation of Dauer Larva Development. (Cold Spring Harbor: Cold Spring Harbor Laboratory Press). Abstract Article

Riddle D.L., Swanson M.M., and Albert P.S. (1981). Interacting genes in nematode dauer larva formation. Nature 290, 668-671. Abstract Article 
Rossi L., Lin K.K., Boles N.C., Yang L., King K.Y., Jeong M., Mayle A., and Goodell M.A. (2012). Less is more: unveiling the functional core of hematopoietic stem cells through knockout mice. Cell Stem Cell 11, $302-317$. Abstract Article

Ruaud A.F., Katic I., and Bessereau J.L. (2011). Insulin/Insulin-like growth factor signaling controls non-Dauer developmental speed in the nematode Caenorhabditis elegans. Genetics 187, 337-343. Abstract Article

Russell J., Vidal-Gadea A.G., Makay A., Lanam C., and Pierce-Shimomura J.T. (2014). Humidity sensation requires both mechanosensory and thermosensory pathways in Caenorhabditis elegans. Proc. Natl. Acad. Sci. U. S. A. 111, 8269-8274. Abstract Article

Schackwitz W.S., Inoue T., and Thomas J.H. (1996). Chemosensory neurons function in parallel to mediate a pheromone response in C. elegans. Neuron 17, 719-728. Abstract Article

Schaedel O.N., Gerisch B., Antebi A., and Sternberg P.W. (2012). Hormonal signal amplification mediates environmental conditions during development and controls an irreversible commitment to adulthood PLoS Biol. 10, e1001306. Abstract Article

Schroeder N.E., and Flatt K.M. (2014). In vivo imaging of Dauer-specific neuronal remodeling in C. elegans. J. Vis. Exp. 91, e51834. Abstract Article

Schroeder N.E., Androwski R.J., Rashid A., Lee H., Lee J., and Barr M.M. (2013). Dauer-Specific dendrite arborization in $C$. elegans is regulated by KPC-1/Furin. Curr. Biol. 23, 1527-1535. Abstract Article

Swanson M.M., and Riddle D.L. (1981). Critical periods in the development of the Caenorhabditis elegans dauer larva. Dev. Biol. 84, 27-40. Abstract Article

Thomas J.H., Birnby D.A., and Vowels J.J. (1993). Evidence for parallel processing of sensory information controlling dauer formation in Caenorhabditis elegans. Genetics 134, 1105-1117. Abstract Article

Trent C., Tsuing N., and Horvitz H.R. (1983). Egg-laying defective mutants of the nematode Caenorhabditis elegans. Genetics 104, 619-647. Abstract Article

Vowels J.J., and Thomas J.H. (1992). Genetic analysis of chemosensory control of dauer formation in Caenorhabditis elegans. Genetics 130, 105-123. Abstract Article

Vowels J.J., and Thomas J.H. (1994). Multiple chemosensory defects in daf-11 and daf-21 mutants of Caenorhabditis elegans. Genetics 138, 303-316. Abstract Article

Wang J., and Kim S.K. (2003). Global analysis of dauer gene expression in Caenorhabditis elegans. Development 130, 1621-1634. Abstract Article

Zhang X., Noguez J.H., Zhou Y., and Butcher R.A., (2013). Analysis of ascarosides from Caenorhabditis elegans using mass spectrometry and NMR spectroscopy. Methods Mol. Biol. 1068, 71-92. Abstract Article

All WormBook content, except where otherwise noted, is licensed under a Creative

Commons Attribution License. 